OPEN ACCESS

Edited by:

Aijun Zhang,

United States Department of

Agriculture, United States

Reviewed by:

Stephen A. Teale,

State University of New York,

United States

Alvin Kah-Wei Hee,

Putra Malaysia University, Malaysia

${ }^{*}$ Correspondence:

Maria C. Blassioli-Moraes

carolina.blassioli@embrapa.br

Specialty section: This article was submitted to

Chemical Ecology,

a section of the journa

Frontiers in Ecology and Evolution

Received: 07 May 2018

Accepted: 20 June 2018

Published: 24 July 2018

Citation:

Magalhães DM, Borges $M$,

Laumann RA, Woodcock CM,

Withall DM, Pickett JA, Birkett MA and

Blassioli-Moraes MC (2018)

Identification of Volatile Compounds

Involved in Host Location by

Anthonomus grandis (Coleoptera: Curculionidae). Front. Ecol. Evol. 6:98.

doi: 10.3389/fevo.2018.00098

\section{Identification of Volatile Compounds Involved in Host Location by Anthonomus grandis (Coleoptera: Curculionidae)}

\author{
Diego M. Magalhães ${ }^{1,2}$, Miguel Borges ${ }^{1}$, Raúl A. Laumann ${ }^{1}$, Christine M. Woodcock ${ }^{3}$, \\ David M. Withall ${ }^{3}$, John A. Pickett ${ }^{3}$, Michael A. Birkett ${ }^{3}$ and Maria C. Blassioli-Moraes ${ }^{1 *}$ \\ 1 Laboratório de Semioquímicos, Núcleo Temático de Controle Biológico, Embrapa Recursos Genéticos e Biotecnologia, \\ Brasilia, Brazil, ${ }^{2}$ Departamento de Zoologia, Instituto de Ciências Biológicas, Universidade de Brasilia, Brasilia, Brazil, \\ ${ }^{3}$ Department of Biointeractions and Crop Protection, Rothamsted Research, Harpenden, United Kingdom
}

Phytophagous insects rely on plant volatiles to locate suitable hosts upon which to feed or oviposit. The boll weevil, Anthonomus grandis, is the main pest on cotton crops in the Neotropical region and is attracted to host plant volatiles, especially herbivore-induced volatiles from reproductive cotton. Behavioral and electrophysiological responses of the boll weevil were evaluated with the aim of identifying the compounds responsible for host location. Ten compounds elicited antennal responses from A. grandis, but only six were required to elicit a full behavioral response, namely: $(R)$-linalool, (E)-4,8-dimethyl-1,3,7-nonatriene (DMNT), methyl salicylate, $(E)-(1 R, 9 S)$-caryophyllene, geranylacetone and (E-E)-4,8,12-trimethyl-1,3,7,11-tridecatetraene (TMTT). A synthetic blend comprising these six compounds was as attractive as the sample of cotton reproductive stage volatiles. These data are discussed in the context of insect host location and crop protection.

Keywords: cotton, kairomone, herbivore-induced plant volatiles, insect-plant interaction, semiochemicals

\section{INTRODUCTION}

Volatile organic compounds (VOCs) play a major role in plant-insect ecological interactions, especially for phytophagous insects (herbivores) that usually rely on plant volatiles to locate suitable hosts upon which to feed or oviposit (Bruce et al., 2005). Herbivores are able to discriminate between host and non-host plants by using their olfactory system, dealing with a complex background and overlapping signals within the odor landscape (Bruce and Pickett, 2011). Detection of VOCs by these organisms occurs via olfactory receptor neurons (ORNs) that are mainly located on the antennae. The ORNs act in the transduction of chemical signals into electrical signals, allowing the development of behavioral responses (Hallem et al., 2006). Tremendous progress has been made in understanding insect olfaction mechanisms, leading to increasing interest into how insects are affected by behaviorally active compounds and raising opportunities for applying this knowledge into integrated pest management (IPM) strategies (Rodriguez-Saona and Stelinski, 2009). 
Interestingly, herbivores usually rely on ubiquitous plant VOCs rather than on compounds taxonomically related to their hosts (Bruce et al., 2005). As plants usually show temporal and spatial variability in their volatile composition due to both biotic and abiotic stresses, herbivores need to have behavioral plasticity to perceive these variations and discriminate host from non-host plants, host phenology and physiology (Gouinguené and Turlings, 2002; Dudareva et al., 2004; Rostás et al., 2006; Webster et al., 2010; Bruce and Pickett, 2011; Michereff et al., 2011; Magalhães et al., 2016). Therefore, the elucidation of the mechanisms of chemical communication between insects and plants could provide tools for sustainable solutions in modern agriculture (Piñero and Prokopy, 2003). A key issue for the understanding of insect and plant interactions mediated by VOCs is to determine which are the biologically relevant compounds for host plant location within a complex blend of volatiles. Finding the active compounds is not an easy task, but is an extremely important step for the use of plant VOCs in IPM practices (Collatz and Dorn, 2013).

The cotton boll weevil, Anthonomus grandis Boh. (Coleoptera: Curculionidae), is the main pest on cotton crops in the Neotropical region, destroying cotton squares and bolls. Due to the high reproductive rate of adults and endophytic behavior of the immature stages, infestation levels can increase rapidly (Beltrão and Azevedo, 2008). Furthermore, A. grandis has the capacity to withstand fallow periods between crops, feeding on pollen of alternative plants, which can lead to potential outbreaks in the subsequent cotton season (Ribeiro et al., 2010). In Brazil, farmers have adopted heavy spraying of insecticides to control A. grandis (Papa and Celoto, 2015) and its aggregation pheromone is used for population monitoring (Rodrigues and Miranda, 2015). However, when cotton reaches the reproductive stage, there is a decline in the boll weevil's response to pheromone traps (Rummel and Curry, 1986), suggesting that plant attractants as well as the natural pheromone-producing weevils in the crop play a role in A. grandis colonization in cotton.

Several studies have shown that cotton volatiles from the reproductive stage have a great influence on boll weevil foraging behavior and that adult males and females prefer herbivoreinduced volatiles over constitutive cotton volatiles (McKibben et al., 1977; Magalhães et al., 2012, 2016; Silva et al., 2015). Weevil dispersion from natural refuge areas to the crop begins with cotton squaring. At this stage of cotton development, the boll weevil detects a change in the volatile profile, i.e., a decrease in the production of the acyclic homoterpenes, as the starting point for the colonization process (Magalhães et al., 2016). Once in the crop, weevils begin to feed and produce the aggregation pheromone, which together with cotton VOCs, attract more individuals, thereby increasing infestation levels (Tumlinson et al., 1969; Rummel and Curry, 1986).

A large amount of work on the behavior of boll weevils has been previously published. However, cotton VOCs involved in boll weevil attraction to the host plant have not yet been conclusively identified. Electrophysiological assays have demonstrated that the boll weevil antennae respond to cotton VOCs, such as green leaf volatiles (1-hexanol, cis-2-hexen-1ol, cis-3-hexen-1-ol, trans-2-hexenal and trans-2-hexen-1-ol), monoterpenes (limonene and trans- $\beta$-ocimene), sesquiterpenes ( $\beta$-bisabolol and $\beta$-caryophyllene), and aromatic compounds (acetophenone and benzaldehyde) (Dickens, 1984, 1989, 1990). However, of all the EAG-active compounds only $\beta$-bisabolol showed behavioral activity attracting male boll weevils (Dickens, 1986). The other compounds were inactive when tested alone against solvent control in laboratory assays or in field traps (Dickens, 1986, 1989). Moreover, trans-2-hexen-1ol, 1-hexanol, cis-3-hexen-1-ol and $\beta$-bisabolol alone in association with A. grandis' aggregation pheromone increased the capture of boll weevils in traps relative to the pheromone alone (Dickens, 1986, 1989). A field test using traps baited with cotton oil showed that cotton VOCs are attractive to emerging overwintered and lateseason migrating boll weevils (McKibben et al., 1977). In light of these observations, the identification of cotton VOCs attractive to the boll weevil would facilitate the understanding of boll weevilcotton plant interactions and the development of alternative methods for semiochemical-based weevil management, e.g., enrichment of aggregation pheromone traps with plant volatiles. The discovery that plant odors can enhance the attractiveness of pheromones allowed the establishment of new technologies for the monitoring and mass collection of pests (Piñero and Prokopy, 2003). Therefore, the objective of the present study was to identify cotton plant attractants for A. grandis.

\section{MATERIALS AND METHODS}

\section{Insect Rearing}

Boll weevils were reared in plastic containers on an artificial diet [a mixture of agar, beer yeast, wheat germ, soy protein, glucose, ascorbic and sorbic acid, Nipagin, flour from the embryo of cottonseed (Pharmamedia ${ }^{\circledR}$, Traders Protein, USA), Wesson salt mixture, Vanderzant vitamin mixture and water, (Schmidt et al., 2001)] under controlled conditions $\left(25 \pm 1^{\circ} \mathrm{C}, 60 \pm 10 \% \mathrm{RH}\right.$, and 14:10 L:D). Newly molted adults were sexed by the tergalnotch method (Sappington and Spurgeon, 2000), transferred to $250 \mathrm{ml}$ plastic cages (15 insects/cage), and fed with the artificial diet. Food and water were changed three times per week. To prevent interactions between sexes, males were kept in separate cages from females after the imaginal molt. In all experiments, 10-15-day-old virgin weevils were used. Genetic diversity might have been very similar, as no field weevils were added to the laboratory colony during the experiments.

\section{Plants}

Cotton, Gossypium hirsutum L. (var. Delta Opal), was grown individually in 11 pots filled with soil and an organic substrate (in a proportion of 1:1). Plants were kept in a greenhouse under semi-controlled conditions $\left(27 \pm 1^{\circ} \mathrm{C}\right.$ and 14:10 L: D). Laboratory experiments were performed using 6-week-old vegetative cotton plants (up to six expanded true leaves) and 12 -week-old reproductive cotton plants (presence of squares).

\section{Dynamic Headspace Collection}

Volatile organic compounds (VOCs) were collected from boll weevil-damaged cotton plants upon infestation with two 10-15-day-old adult virgin female boll weevils. For each 
collection, a polyethylene terephthalate (PET) oven bag (250 $\times 380 \mathrm{~mm}$, Sainsbury's, UK) was carefully placed over a single plant and sealed around the stem using wire. In one of the top corners of the bag, a hole was made to accommodate a Porapak Q adsorbent tube (50 mg, 50-80 mesh, Supelco, PA, USA). Charcoal-filtered air was pumped in at $1.21 . \mathrm{min}^{-1}$ and drawn out at $0.51 . \mathrm{min}^{-1}$ through the adsorbent tube. The difference in flow created a slight positive pressure to ensure that unfiltered air did not enter the system. Prior to use, the oven bags were baked at $180^{\circ} \mathrm{C}$ for $2 \mathrm{~h}$ and the Porapak Q tubes were eluted with redistilled hexane and heated at $132^{\circ} \mathrm{C}$ for $2 \mathrm{~h}$ to remove contaminants. Cotton volatiles were collected over a period of 4 days, with Porapak Q tubes being replaced every $24 \mathrm{~h}$ and eluted with redistilled hexane $(0.5 \mathrm{ml})$. VOCs were collected from three cotton plants each at the vegetative and reproductive stage. Samples were stored in vials at $-20^{\circ} \mathrm{C}$ until used in electrophysiological and behavioral bioassays and chemical analysis.

\section{Gas Chromatography Analysis}

Volatile samples from cotton were analyzed on an Agilent $6890 \mathrm{~N}$ equipped with a cool-on-column (COC) injector, a flame ionization detector (FID), and a non-polar DB-1 column $(50 \mathrm{~m} \times$ $0.32 \mathrm{~mm}$ ID, $0.52 \mu \mathrm{m}$ film thickness, J \& W Scientific). The oven temperature was maintained at $30^{\circ} \mathrm{C}$ for $1 \mathrm{~min}$, programmed at $5^{\circ} \mathrm{C} \cdot \mathrm{min}^{-1}$ to $150^{\circ} \mathrm{C}$ and held for $0.1 \mathrm{~min}$, then at $10^{\circ} \mathrm{C} \cdot \mathrm{min}^{-1}$ to $230^{\circ} \mathrm{C}$. The carrier gas was helium. The stereochemistry of linalool was determined by using an Agilent $6890 \mathrm{~N}$ equipped with a COC injector and a FID, fitted with a $\beta$-cyclodextrin chiral capillary column $(30 \mathrm{~m} \times 0.25 \mathrm{~mm}$ ID, $0.25 \mu \mathrm{m}$ film thickness, Supelco, USA). The GC oven was maintained at $30^{\circ} \mathrm{C}$ for $1 \mathrm{~min}$ and programmed at $5^{\circ} \mathrm{C} \cdot \mathrm{min}^{-1}$ to $150^{\circ} \mathrm{C}$, held for $0.1 \mathrm{~min}$ and then at $10^{\circ} \mathrm{C} \cdot \mathrm{min}^{-1}$ where it was held for $22 \mathrm{~min}$. The carrier gas was helium. A $1 \mu$ l aliquot of a solution that contained both enantiomers of linalool i.e., $(R)$ and $(S)$ was injected onto the chiral GC column to establish that successful separation of the enantiomers took place. This was followed by GC peak enhancement using the volatile samples.

\section{Coupled Gas \\ Chromatography-Electroantennographic Detection (GC-EAD)}

Electroantennogram recordings were made with $\mathrm{Ag}-\mathrm{AgCl}$ glass electrodes filled with Ringer's solution without glucose. A boll weevil antenna was excised and mounted between the electrodes. The extreme tips of flagellum and scape were cut off with a scalpel to ensure good electrical contact. Separation of the volatiles was achieved on an Agilent $6890 \mathrm{~N}$ gas chromatograph equipped with a cool-on-column injector, a FID and a non-polar DB-1 column $(50 \mathrm{~m} \times 0.32 \mathrm{~mm}$ ID, $0.52 \mu \mathrm{m}$ film thickness, J \& W Scientific). The GC oven temperature was maintained at $30^{\circ} \mathrm{C}$ for $2 \mathrm{~min}$ and then programmed to rise at $5^{\circ} \mathrm{C} \cdot \mathrm{min}^{-1}$ to $100^{\circ} \mathrm{C}$ and then at $10^{\circ} \mathrm{C} \cdot \mathrm{min}^{-1}$ to $250^{\circ} \mathrm{C}$. The carrier gas was helium. Responses were measured in $\mathrm{mV}$ deflections and the signals were passed through a high-impedance amplifier (UN-06, Syntech, The Netherlands), and simultaneous recordings of the EAD and
FID responses were analyzed with a customized software package (EAD version 2.3, Syntech, The Netherlands). Three coupled runs using volatile samples were undertaken for male and female boll weevils. The volatile samples consisted of volatiles from $72-$ $96 \mathrm{~h}$ boll weevil-damaged reproductive cotton plants, because in a previous study weevils preferred these volatiles over undamaged or herbivore-damaged vegetative cotton volatiles (Magalhães et al., 2012).

\section{Coupled Gas Chromatography-Mass Spectrometry (GC-MS)}

Volatile samples from cotton were analyzed using a GC (Agilent $6890 \mathrm{~N}$ ) equipped with capillary column (DB-1, $50 \mathrm{~m} \times 0.32 \mathrm{~mm}$ ID, $0.52 \mu \mathrm{m}$ film thickness, J \& W Scientific) coupled to a mass spectrometer detector (Agilent $5973 \mathrm{MSD}$ ). Ionization was by electron impact $\left(70 \mathrm{eV}\right.$, source temperature at $\left.250^{\circ} \mathrm{C}\right)$. The oven temperature was maintained at $30^{\circ} \mathrm{C}$ for $5 \mathrm{~min}$ and then programmed at $5^{\circ} \mathrm{C} \cdot \mathrm{min}^{-1}$ to $250^{\circ} \mathrm{C}$. Tentative identifications were made by comparison of spectra with mass spectral library databases (NIST, 2008) and confirmed by GC peak enhancement using authentic standards.

\section{Chemicals}

Authentic chemical standards of $\alpha$-pinene (98\%), ocimene (90\%), linalool (98\%) and geranylacetone (96\%) were purchased from Sigma-Aldrich Inc. (Steinheim, Germany). (Z)-3-Hexenyl acetate (99\%) and methyl salicylate (98\%) were purchased from Avocado Research Chemicals Ltd. (Lancashire, UK). (E)-(1R,9S)-Caryophyllene (95\%) was purchased from Pfaltz \& Bauer Inc. (Connecticut, USA). (E)-4,8-Dimethyl-1,3,7-nonatriene (DMNT) (95\%) and (E,E)-4,8,12-trimethyl-1,3,7,11-tridecatetraene (TMTT) (97\%) were synthesized from geraniol and (E,E)-farnesol, respectively (Leopold, 1990). (E)-2-methylbutanal oxime (90\%) was synthesized from 2-methylbutanal by reaction with hydroxylamine (Voegel, 1956).

\section{Electrophysiological Responses of the Boll Weevil to Identified Compounds (EAG)}

The electrophysiological activity of identified compounds was confirmed using the set-up described above (see coupled GCEAD). The stimulus delivery system employed a piece of filter paper $\left(1 \times 1 \mathrm{~cm}^{2}\right)$ in a disposable Pasteur pipette cartridge. The stimuli were delivered over the preparation in a constant 1 1. $\mathrm{min}^{-1}$ airstream and applied ( $2 \mathrm{~s}$ duration) every $30 \mathrm{~s}$ interval. A $10 \mu \mathrm{l}$ aliquot of standard solutions of each test compounds (at $1 \mathrm{mg} \cdot \mathrm{ml}^{-1}$ in distilled hexane) were applied to strips of filter paper, with the solvent being allowed to evaporate for $60 \mathrm{~s}$ before the strip was placed into the cartridge. The test compounds were alternated with hexane controls to allow for the decline in EAG response of the preparations with time. A mean of the preceding and following hexane control response was calculated for each test compound. Antennae from 10 virgin females and 10 virgin males of 10-15-day-old were tested. 


\section{Olfactometer Bioassays}

Behavioral assays were carried out using a glass Y-tube olfactometer to determine the responses of 10-15-day-old adult male and female boll weevils to volatile samples collected from reproductive and vegetative stage cotton, and to synthetic blends that were comprised of the identified electrophysiologicallyactive compounds. Each arm of the olfactometer contained a filter paper loaded either with $10 \mu \mathrm{L}$ of the volatile sample, synthetic blend or solvent control (hexane). Charcoal-filtered and humidified air was pushed into the system at $0.51 . \mathrm{min}^{-1}$ and pulled out at $0.11 . \mathrm{min}^{-1}$. Detailed construction of the olfactometer and procedures of bioassays have been described elsewhere (Magalhães et al., 2012). Weevils were starved for $24 \mathrm{~h}$ prior to bioassays and a single boll weevil was introduced at the base of the trunk of the Y-tube olfactometer. Weevils were observed for $10 \mathrm{~min}$ and the first choice and residence time were noted. Each weevil was used only once and the filter paper replaced after five repetitions. Both sexes were assayed until 40 males and 40 females had responded (positive chemotaxis). After five repetitions, the Y-tube olfactometer and the side on which the treatment was presented was swapped to avoid any positional bias. The following experiments were conducted: (1) synthetic blend at the same concentration and ratio as found in the volatile sample collected from boll weevil-damaged reproductive cotton (Mix1) vs. hexane; (2) Mix1 10 times concentrated $\left(\operatorname{Mix} 1^{10+}\right)$ vs. hexane; (3) Mix1 10 times diluted (Mix $\left.1^{10-}\right)$ vs. hexane; (4) Mixl vs. volatile sample collected from boll weevildamaged reproductive cotton (BWD-Rep) and (5) Mixl vs. volatile sample collected from boll weevil-damaged vegetative cotton (BWD-Veg). The volatile samples used consisted of volatiles collected over a $96 \mathrm{~h}$ period from boll weevil-damaged vegetative and reproductive cotton plants. Herbivore-induced volatiles were used because previously it was shown that the boll weevil prefers herbivore-induced over constitutive cotton volatiles (Magalhães et al., 2012). The initial blend (Mix1) was comprised of 10 compounds: (E)-2-methylbutanal oxime, $\alpha$-pinene, $(Z)$-3-hexenyl acetate, $(E)$-ocimene, $(R)$ linalool, (E)-4,8-dimethyl-1,3,7-nonatriene (DMNT), methyl salicylate, $(E)$ - $(1 R, 9 S)$-caryophyllene, geranylacetone, and $(E, E)$ 4,8,12-trimethyl-1,3,7,11-tridecatetraene (TMTT) (Table 1). To investigate whether all EAG-active compounds in Mix1 were necessary for boll weevil attraction, individual compounds were progressively removed from this mixture (Table 1). If the deleted compound led to a loss of attraction, then it was reintroduced in the mixture and another compound was removed in the next bioassay. The resulting reduced blends were assayed against a hexane control. The removed compounds were chosen randomly until all compounds were progressively deleted. To verify whether the Final Mix (six-component blend), which resulted after the stepwise deletion of single compounds, was still as attractive as Mix1 (initial 10-component blend), the two blends were compared in dual-choice bioassays. Each component of the six-component Final Mix was also individually tested against hexane control. Additionally, the Final Mix was tested against a volatile sample collected from cotton (BWD-Rep). Finally, as the Final Mix is the result of a stepwise deletion of single compounds from Mix1 and that these two mixtures exert the same behavioral response on the boll weevil, x10 concentrations solutions were only tested for Mix1.

\section{Statistical Analysis}

The total amount of released VOCs from each treatment was compared using General Linear Models (GLM), and Deviance Analyses with gamma distribution and inverse as link function (R-Studio Inc., version 0.99.903). The electrophysiological responses of the boll weevil to control and test compounds were analyzed using analysis of variance (ANOVA) and the means were compared using Tukey's 95\% confidence (GenStat, 17th edition). Statistical analysis of the data of the first choice of boll weevils in olfactometer bioassays were carried out by logistic regression and Wald's Chi-square test to evaluate the hypotheses of non-preference (50\% of choices of each arm) (R-Studio Inc., version 0.99.903). Residence time in treatment and control arms was compared by Paired-t-test (R-Studio Inc., version 0.99.903).

TABLE 1 | Components of the synthetic volatile blends comprising of the electrophysiologically active compounds for Anthonomus grandis.

\begin{tabular}{|c|c|c|c|c|c|c|c|c|c|c|c|c|c|}
\hline Compounds & Amount (ng/10 $\mu \mathrm{L})$ & Mix1 & Mix2 & Mix3 & Mix4 & Mix 5 & Mix 6 & Mix 7 & Mix 8 & Mix 9 & Mix110 & Mix111 & Final Mix \\
\hline$(R)$-Linalool & 2.60 & $x$ & $x$ & $X$ & $x$ & $X$ & $x$ & $x$ & $x$ & $x$ & $x$ & - & $x$ \\
\hline $\mathrm{DMNT}^{\dagger}$ & 29.4 & $X$ & $x$ & $X$ & $x$ & $X$ & $x$ & $X$ & $X$ & $X$ & - & $X$ & $X$ \\
\hline TMTT‡ & 66.5 & $x$ & $x$ & $X$ & $x$ & $x$ & $x$ & $X$ & $x$ & - & 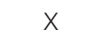 & $x$ & $x$ \\
\hline$(E)-(1 R, 9 S)$-Caryophyllene & 40.9 & $x$ & $x$ & $x$ & $x$ & $x$ & $x$ & $x$ & - & $x$ & $x$ & $x$ & $x$ \\
\hline (Z)-3-Hexenyl acetate & 13.5 & $x$ & $x$ & $x$ & $x$ & $x$ & $x$ & - & - & - & - & - & - \\
\hline Methyl salicylate & 2.30 & $X$ & $x$ & $X$ & $X$ & $X$ & - & $X$ & $x$ & $X$ & $x$ & $x$ & $x$ \\
\hline Geranylacetone & 2.20 & $x$ & $x$ & $x$ & $x$ & - & $x$ & $x$ & $x$ & $x$ & $x$ & $x$ & $x$ \\
\hline (E)-2-Methylbutanal oxime & 0.80 & $x$ & $x$ & $x$ & - & - & - & - & - & - & - & - & - \\
\hline$(E)$-Ocimene & 58.6 & $x$ & $x$ & - & - & - & - & - & - & - & - & - & - \\
\hline$\alpha$-Pinene & 61.8 & $x$ & - & - & - & - & - & - & - & - & - & - & - \\
\hline
\end{tabular}

${ }^{\dagger}(E)$-4,8-dimethyl-1,3,7-nonatriene.

$\neq(E, E)$-4, 8, 12-trimethyltrideca-1,3,7,11-tetraene. 


\section{RESULTS}

\section{Identification of Cotton Compounds in Air-Entrainment Samples}

Chemical analyses of VOC samples collected from vegetative and reproductive stages of cotton revealed no qualitative differences (Figure 1A). However, the total amount of VOCs produced by boll weevil-damaged cotton plants at the vegetative and reproductive stages were significantly different (ANODEV $\chi^{2}=10.405, d f=1, P=0.0012$ ) (Figure 1B), with greater amounts emitted by damaged vegetative plants during $24-48$ and 72-96 h volatile collection periods.

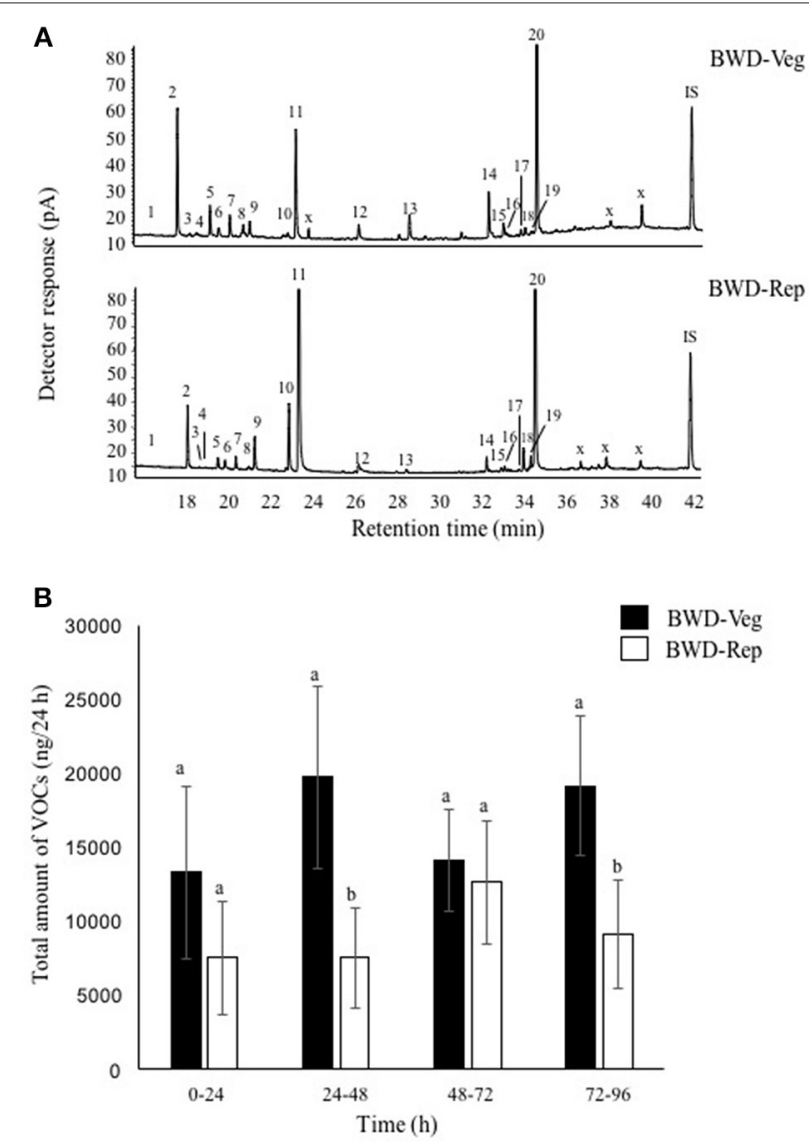

FIGURE 1 | Qualitative and quantitative profiles of herbivore-induced volatiles from vegetative and reproductive stages of cotton plants. (A) Representative chromatograms of air-entrainment of boll weevil-damaged cotton at 72-96 h. Numbers represent compounds: (1) (E)-2-methylbutanal oxime, (2) $\alpha$-pinene, (3) benzaldehyde, (4) camphene, (5) $\beta$-pinene, (6) myrcene, (7) (Z)-3-hexenyl acetate, (8) limonene, (9) (E)-ocimene, (10) (R)-linalool, (11) DMNT, (12) methyl salicylate, (13) indole, (14) (E)-(1R,9S)-caryophyllene, (15) geranylacetone, (16) $\alpha$-humulene, (17) $\delta$-guaiene, (18) $\delta$-cadinene, (19) nerolidol, and (20) TMTT. (B) Amounts (mean \pm SEM) of total volatiles from boll weevil-damaged cotton plants. Means with the same letter within a given time that the plants were sampled (0-24, 24-48, 48-72, or 72-96 h after treatment was started) are not different $(P>0.05)$ by General Linear Model (GLM) and ANODEV and mean comparisons by contrast analyses. BWD-Veg, boll weevil-damaged vegetative cotton. BWD-Rep, boll weevil-damaged reproductive cotton.

\section{Identification of Electrophysiologically Active Compounds in Volatile Samples}

Coupled GC-EAD using male and female boll weevil antennae with cotton volatile samples revealed the presence of 10 electrophysiologically active compounds from reproductive boll weevil-damaged cotton plants (Figure 2). Coupled GC-MS and GC peak enhancement, including using enantioselective (chiral) GC, using authentic standards revealed the identity of these compounds as (E)-2-methylbutanal oxime, $\alpha$-pinene, $(Z)$-3-hexenyl acetate, $(E)$-ocimene, $(R)$-linalool, DMNT, methyl salicylate, $(E)-(1 R, 9 S)$-caryophyllene, geranylacetone and TMTT.

\section{Electrophysiological Responses of the Boll Weevils to Identified Compounds}

Male and female boll weevil antennae elicited statistically significant electrophysiological responses to all 10 identified EAG-active cotton compounds at a stimulus concentration of $1 \mathrm{mg} \cdot \mathrm{ml}^{-1}$ in relation to hexane (Figure 3). There was no significant difference in EAG responses between male and female weevils.

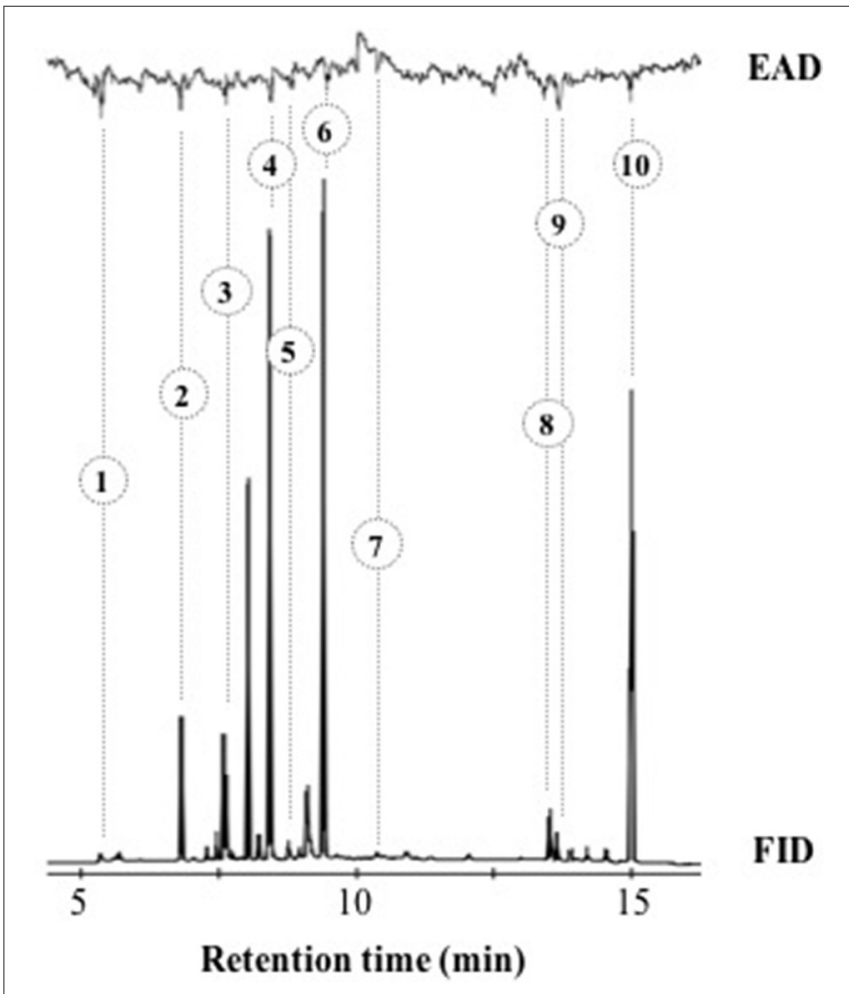

FIGURE 2 | Representative GC-EAD recording of Anthonomus grandis responses to reproductive boll weevil-damaged cotton volatiles. As male and female responses were not different, only one trace is shown. The FID peaks marked are those which elicited responses in two or more runs: $1=(E)$-2-methylbutanal oxime, $2=\alpha$-pinene, $3=(Z)$-3-hexenyl acetate, $4=(E)$-ocimene, $5=(R)$-linalool, $6=(E)$-4,8-dimethyl-1,3,7-nonatriene (DMNT), $7=$ methyl salicylate, $8=(E)-(1 R, 9 S)$-caryophyllene, $9=$ geranylacetone, and $10=(E, E)$-4,8,12-trimethyl-1,3,7,11-tridecatetraene (TMTT). The stereochemistry of linalool was inferred from a separate analysis on a chiral column. 


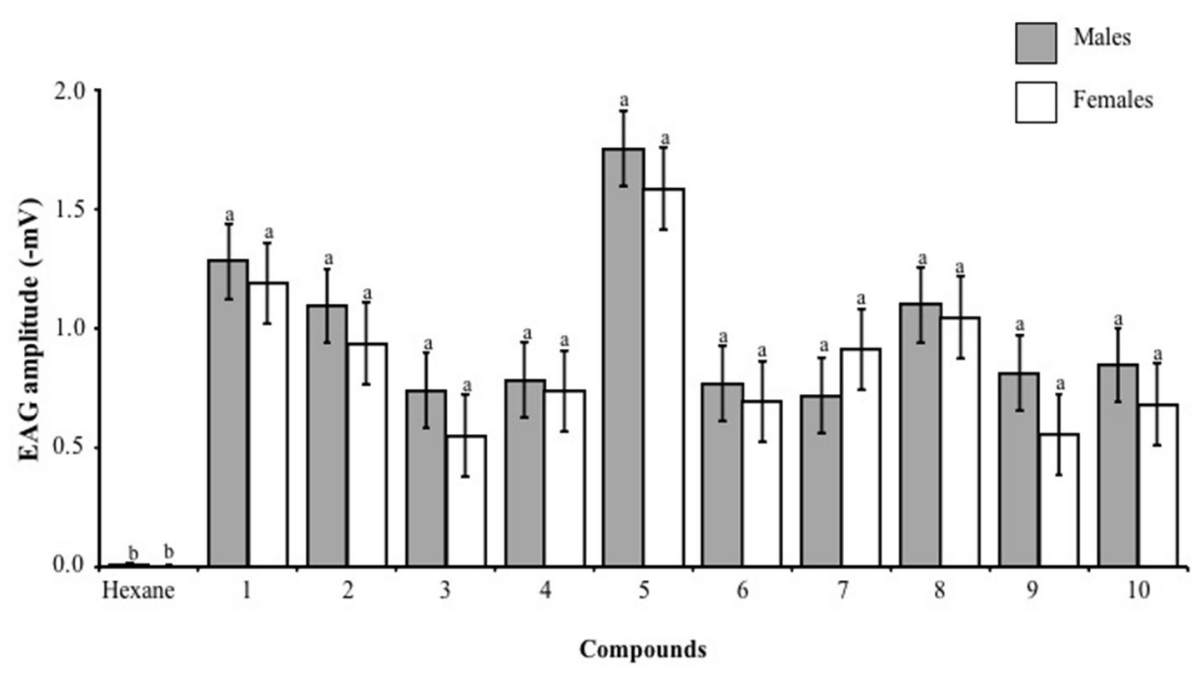

FIGURE 3 | Electrophyisological responses (-mV $\pm \mathrm{SE}$ ) of male and female Anthonomus grandis antennae to compounds identified in reproductive boll weevil-damaged cotton plants volatiles by coupled GC-EAD and GC-MS $(N=10)$. Compounds: $1=(E)$-2-methylbutanal oxime, $2=\alpha$-pinene, $3=(Z)$-3-hexenyl acetate, $4=(E)$-ocimene, $5=(R)$-linalool, $6=(E)$-4,8-dimethyl-1,3,7-nonatriene (DMNT), $7=$ methyl salicylate, $8=(E)$ - $(1 R, 9 S)$-caryophyllene, $9=$ geranylacetone, and $10=(E, E)-4,8,12$-trimethyl-1,3,7,11-tridecatetraene (TMTT). Same letters indicate no significant difference between male and female responses and different letters indicate significant difference between the test compounds and hexane $(P<0.001)$.

A

Mix 1

Mix 1

Mixl

$\operatorname{Mix} 1^{10+}$

$\operatorname{Mix} 1^{10-}$
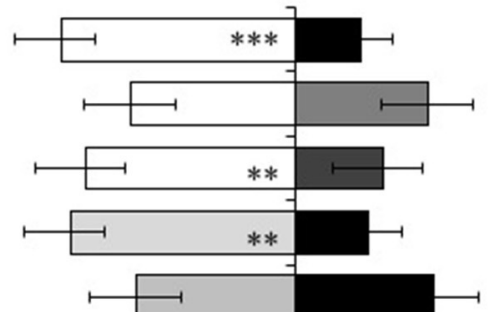

$\begin{array}{lllllllllll}1.0 & 0.8 & 0.6 & 0.4 & 0.2 & 0.0 & 0.2 & 0.4 & 0.6 & 0.8 & 1.0\end{array}$

B

Mix 1

Mixl

Mix 1

$\operatorname{Mix} 1^{10+}$

$\operatorname{Mix} 1^{10-}$

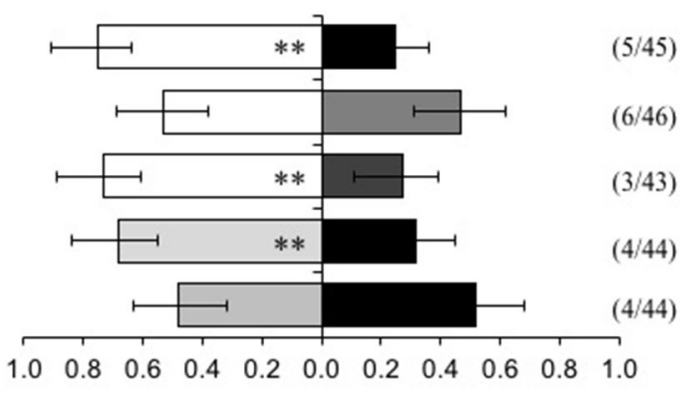

Proportion of boll weevils response
Hexane

BWD-Rep

BWD-Veg

Hexane

Hexane
Hexane

BWD-Rep

BWD-Veg

Hexane

Hexane

FIGURE 4 | First choice of male (A) and female (B) boll weevils, Anthonomus grandis, in a Y-tube olfactometer. Mix1 = synthetic blend at the same concentration and ratio as found in the volatile samples collected from boll weevil-damaged cotton plants at the reproductive stage; Mix $1^{10+}=$ Mix $1 \times 10$ concentrated; Mix $1^{10-}=$ Mix 1 $\times 10$ diluted; BWD-Rep = volatile samples collected from boll weevil-damaged cotton plants at the reproductive stage; BWD-Veg = volatile samples collected from boll weevil-damaged cotton plants at the vegetative stage. Asterisks indicate differences $\left.{ }^{* \star} 0.01>P>0.001,{ }^{\star \star \star} P<0.001\right)$ between pairs of treatments. Bars indicate $95 \%$ of confidence interval. Numbers in parentheses indicate insects that did not respond to either tested treatments/total amount of bioassays. 


\section{Behavioral Responses}

In Y-tube olfactometer bioassays, when the ten-component synthetic blend (Mix1) was used as an odor source, male and female boll weevils preferred the treated area over the hexane control area (males: $\chi^{2}=10.67, d f=1, P=0.001$ and females: $\chi^{2}=9.05, d f=1, P=0.002$ ) (Figure 4), and also spent more time in the treated area (males: $t=3.22, d f=39$, $P=0.002$ and females: $t=1.95, d f=39, P=0.05)$ (Figure 5). When the synthetic blend was presented at a x10 concentration (Mix $\left.1^{10+}\right)$, weevils had the same pattern of response (males: $\chi^{2}=9.05, d f=1, P=0.002$ and females: $\chi^{2}=4.69, d f=1$, $P=0.03$ ), but when the blend concentration was decreased $\mathrm{x} 10$ (Mix $1^{10-}$ ), they showed no preference (males: $\chi^{2}=0.10$, $d f=1, P=0.75$ and females: $\chi^{2}=0.10, d f=1, P=0.75$ ) (Figure 4). Similar results were obtained for residence time, i.e., male and female boll weevils spent more time in the arm containing Mix ${ }^{10+}$ (males: $t=3.11, d f=39, P=0.003$ and females: $t=2.34, d f=39, P=0.02$ ) compared to the hexane control area, and there was no significant preference for Mixl ${ }^{10-}$ when tested vs. the control (males: $t=-0.18$, $d f=39, P=0.85$ and females: $t=1.87, d f=39, P=0.07$ ) (Figure 5).

When Mixl and VOC samples collected from boll weevildamaged cotton at the reproductive stage (BWD-Rep) were tested in dual choice assays, weevils did not show any preference, either for the first choice (males: $\chi^{2}=0.40, d f=1$, $P=0.52$ and females: $\left.\chi^{2}=0.10, d f=1, P=0.75\right)$ (Figure 4) or for the residence time (males: $t=1.60, d f=39$, $P=0.12$ and females: $t=0.08, d f=39, P=0.93$ ) (Figure 5). However, when Mix1 was tested against volatile samples collected from boll weevil-damaged cotton plants at the vegetative stage (BWD-Veg), weevils preferred the arm of the olfactometer containing Mixl over the BWD-Veg volatile samples (males: $\chi^{2}=6.03$, $d f=1, P=0.01$ and females: $\chi^{2}=7.49, d f=1, P=0.006$ ) (Figure 4), and they also spent more time in the Mixl area (males: $t=2.72$, $d f=39$, $P=0.009$ and females: $t=2.33, d f=39, P=0.024)$ (Figure 5).

Both male and female boll weevils preferred the synthetic blends over hexane control for Mix2-4 and Mix7 (Mix2 males: $\chi^{2}=4.69, d f=1, P=0.03$ and females: $\chi^{2}=3.98, d f=1$, $P=0.04$; Mix3 males: $\chi^{2}=3.98, d f=1, P=0.04$ and females: $\chi^{2}=7.49, d f=1, P=0.006$; Mix4 males: $\chi^{2}=4.69, d f=1$, $P=0.03$ and females: $\chi^{2}=6.03, d f=1, P=0.01$; Mix7 males: $\chi^{2}=7.49, d f=1, P=0.006$ and females: $\chi^{2}=8.44, d f=1$, $P=0.003$ ) (Figure 6). The same pattern was observed for the residence time, the weevils spent more time in the area treated with the synthetic blends (Mix2 males: $t=3.03, d f=39$,

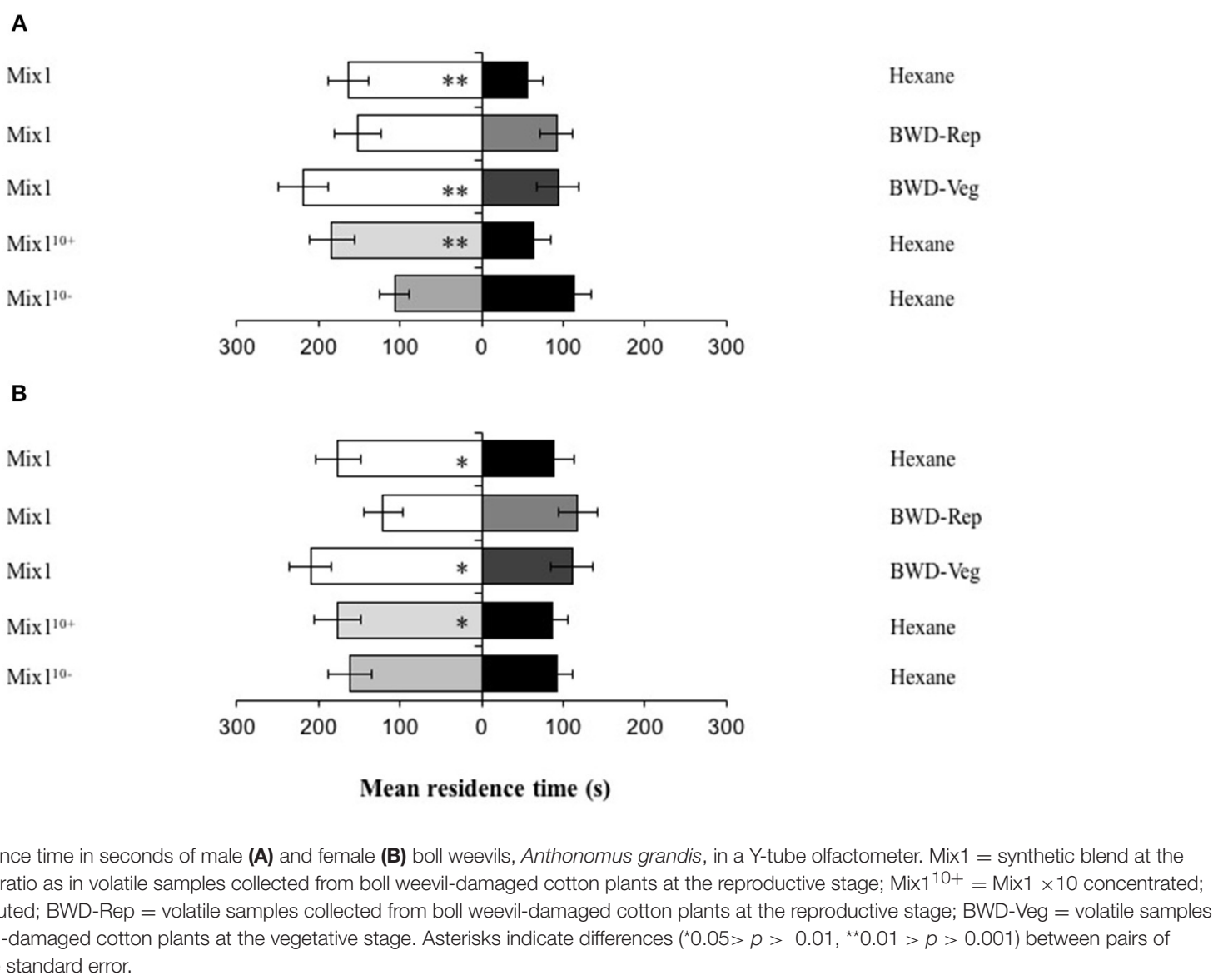




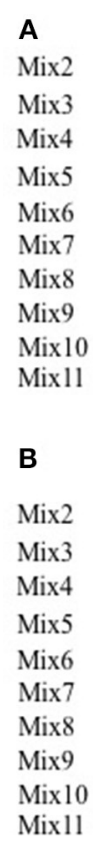

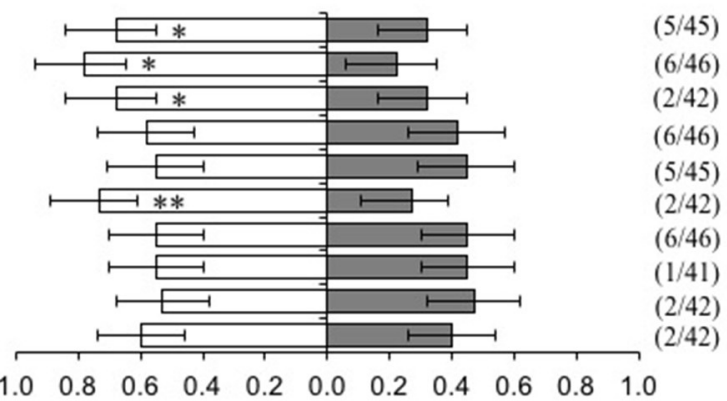

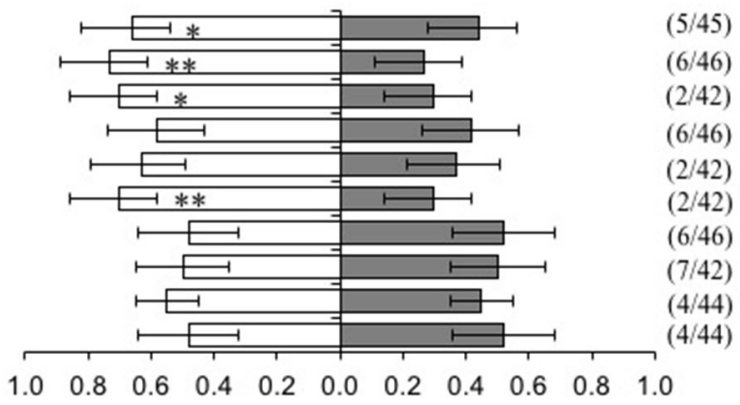

Proportion of boll weevils response
$(5 / 45)$

$\square$ Hexane

$(1 / 41)$

$(2 / 42)$

$(2 / 42)$

$(2 / 42)$

$(6 / 46)$

FIGURE 6 | First choice of male (A) and female (B) boll weevils, Anthonomus grandis, in a Y-tube olfactometer, to synthetic blends at the same concentration and ratio as in volatile samples collected from boll weevil-damaged cotton plants at the reproductive stage (for composition of blends, see Table 1). Asterisks indicate differences ( ${ }^{*} 0.05>P>0.01,{ }^{\star \star} 0.01>P>0.001$ ) between pairs of treatments. Bars indicate $95 \%$ of confidence interval. Numbers in parentheses indicate insects that did not respond to either tested treatments/total amount of bioassays.

$P=0.004$ and females: $t=1.97, d f=39, P=0.05$; Mix3 males: $t=1.98$, df $=39, P=0.05$ and females: $t=2.56$, $d f=39, P=0.01$; Mix4 males: $t=3.24, d f=39, P=0.002$ and females: $t=2.52, d f=39, P=0.01$; Mix7 males: $t=2.07$, $d f=39, P=0.04$ and females: $t=1.93, d f=39, P=0.05)$ (Figure 7). Removal of further compounds, i.e., Mix5-6 and Mix8-11, yielded neither weevil attraction nor repellence, for both the first choice (Figure 6) and residence time (Figure 7) $(P>0.05)$.

No significant difference was observed when the sixcomponent blend (Final Mix) was tested against the tencomponent blend (Mix1), either for the first choice (males: $\chi^{2}=0.10, d f=1, P>0.05$ and females: $\chi^{2}=0.10, d f=1$, $P>0.05$ ) (Figure 8) or residence time (males: $t=-0.79, d f=39$, $P>0.05$ and females: $t=0.83, d f=39, P>0.05)$ (Figure 9). When the six compounds, that comprise the Final Mix, were individually tested against hexane control, neither male nor female boll weevils were attracted to any of the compounds $(P>0.05)$. The volatile samples collected from boll weevildamaged cotton at the reproductive stage (BWD-Rep) were neither more attractive than the Final Mix (males: $\chi^{2}=0.10$, $d f=1, P>0.05$ and females: $\left.\chi^{2}=0.10, d f=1, P>0.05\right)$ (Figure 8) nor did they retain more weevils (males: $t=-0.79$, $d f=39, P>0.05$ and females: $t=0.83, d f=39, P>0.05)$ (Figure 9).

\section{DISCUSSION}

Plants produce a wide array of VOCs in different amounts and proportions (Dudareva et al., 2004). Despite the large number of volatile constituents emitted by plants, many studies have demonstrated that insects detect only a small portion of these compounds (Bruce and Pickett, 2011). In our study, we identified 10 VOCs emitted by cotton that elicited electrophysiological responses in adult boll weevils: $(E)$-2-methylbutanal oxime, $\beta$ pinene, $(Z)$-3-hexenyl acetate, $(E)$-ocimene, $(R)$-linalool, DMNT, methyl salicylate, $(E)-(1 R, 9 S)$-caryophyllene, geranylacetone, and TMTT (for full characterization of cotton constitutive and herbivore-induced volatiles at vegetative and reproductive stages, see Magalhães et al., 2012). The identified compounds are ubiquitous amongst plant species and are not exclusive to any particular taxonomic group. They can be frequently found, both constitutively and in response to biotic stress, in different plant species such as maize, soybean, beans and tobacco (Turlings et al., 2000; Kessler and Baldwin, 2001; Webster et al., 2008; Michereff et al., 2011). The nature of these compounds suggests that their proportions in blends might be the key information for the boll weevil to locate its host plant in a complex environment saturated with overlapping chemical signals. Previously, Dickens (1986) showed that for certain varieties of cotton, $\beta$-bisabolol, was the major volatile and 


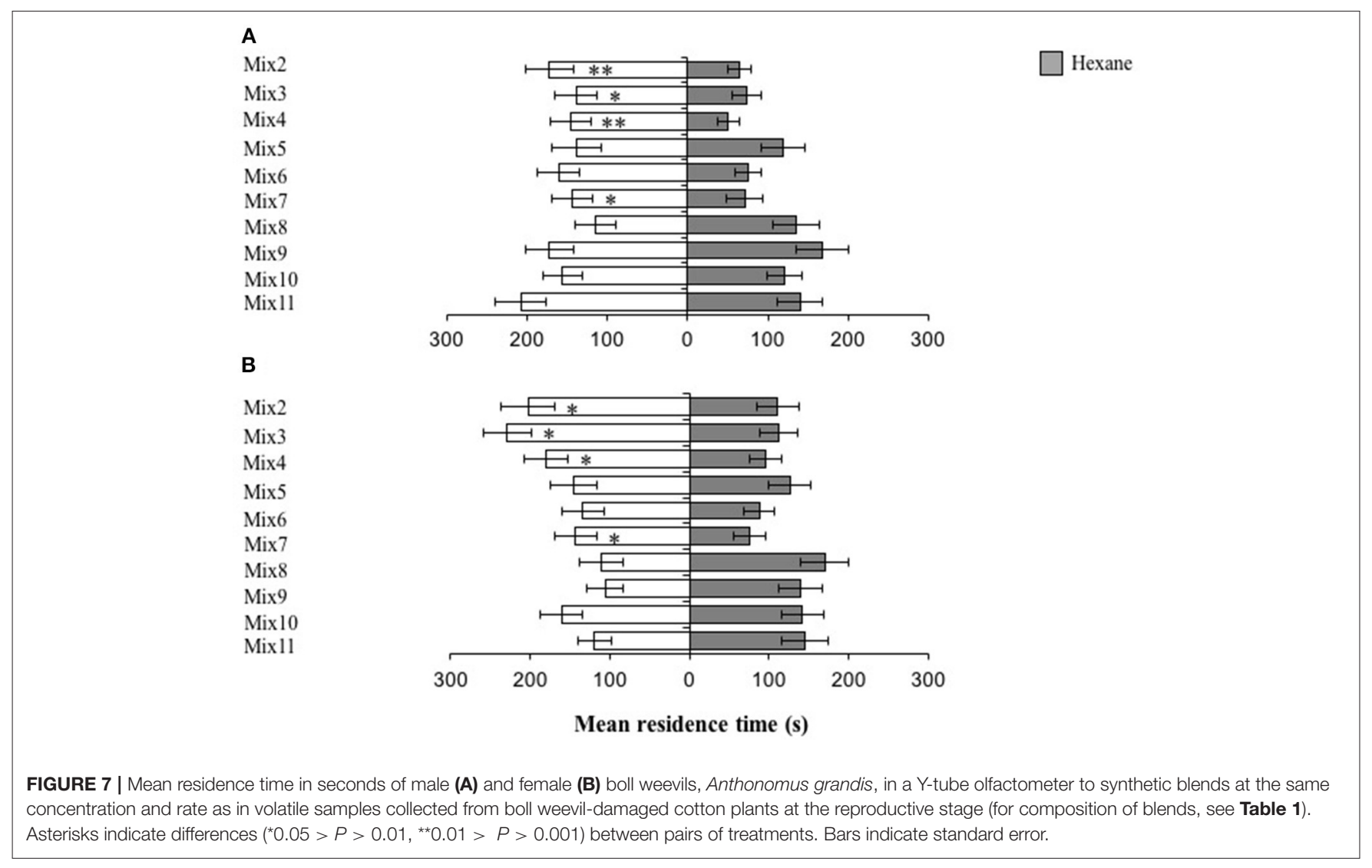

A

Mixl

BWD-Rep

B

Mixl

BWD-Rep

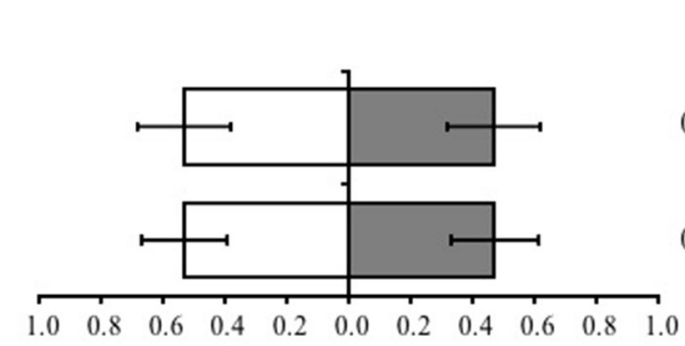

$(1 / 41)$

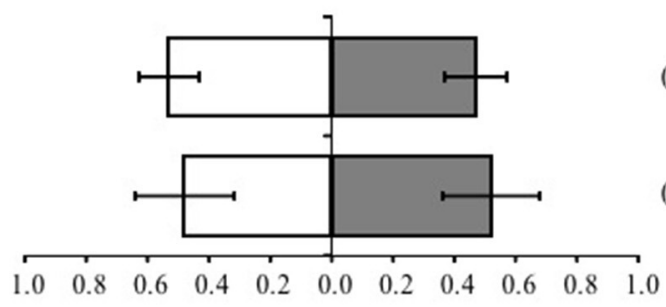

$(2 / 42)$

\section{Proportion of boll weevils response}

FIGURE 8 | First choice of male (A) and female (B) boll weevils, Anthonomus grandis, in a Y-tube olfactometer to synthetic blends at the same concentration and ratio as volatile samples collected from boll weevil-damaged cotton plants at the reproductive stage (for composition of blends, see Table 1). BWD-Rep = volatile samples collected from boll weevil-damaged cotton plants at the reproductive stage. Bars indicate $95 \%$ of confidence interval. Numbers in parentheses indicate insects that did not respond to either tested treatments/total amount of bioassays. 
Final Mix
A

Mixl

BWD-Rep

B

Mixl

BWD-Rep

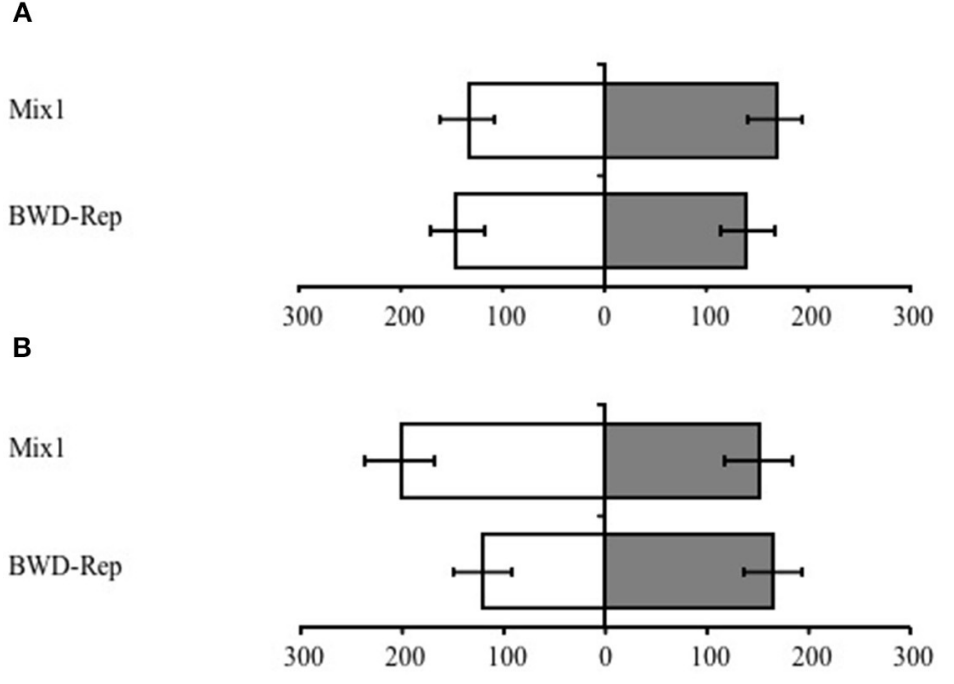

Mean residence time (s)

FIGURE 9 | Mean residence time in seconds of male (A) and female (B) boll weevils, Anthonomus grandis, in a Y-tube olfactometer to synthetic blends at the same concentration and ratio as in volatile samples collected from boll weevil-damaged cotton plants at the reproductive stage (for composition of blends, see Table 1). BWD-Rep = volatile samples collected from boll weevil-damaged cotton plants at the reproductive stage. Bars indicate standard error.

was attractive to male boll weevils. However, this compound was not identified in air-entrainment samples of var. Delta Opal and six other Brazilian varieties (Magalhães, 2016), leading us to further investigate cotton plant attractants for $A$. grandis.

The synthetic blend that comprised all electrophysiologicallyactive compounds contains all the volatile components necessary to attract the boll weevil, as demonstrated in subsequent laboratory bioassays. When Mix1 was compared to the natural sample of reproductive cotton induced-volatiles (BWD-Rep), both attracted A. grandis. However, when Mix1 was compared to the natural sample of vegetative cotton induced-volatiles (BWD-Veg), the synthetic blend, prepared at the same concentration and proportion as in BWD-Rep, was preferred over BWD-Veg.

In nature, the concentration of plant VOCs may exhibit spatiotemporal fluctuations, even in individuals of the same species under similar environmental conditions (Paré and Tumlinson, 1999; Webster et al., 2010). Therefore, to locate their host plant, insects need to have sufficient plasticity to detect and identify these variations as being versions of the same pattern (Riffell et al., 2009). In the bioassays using Mix1 $\mathrm{x} 10$ concentrated $\left(\mathrm{Mixl}^{10+}\right)$, adult weevils continued to be attracted by the synthetic blend. However, using the synthetic blend at concentrations lower than those found in natural environments $\left(\mathrm{Mix}^{10-}\right)$, weevils were no longer attracted. Single cell recordings showed that boll weevil olfactory neurons for host plant volatiles are more sensitive than those that respond to the aggregation pheromone, meaning that plant odor neurons have lower thresholds (1-10 ng) than pheromone receptor neurons (100-1,000 ng) (Dickens, 1990). In addition, it is well-known that boll weevil pheromonal production occurs only after feeding (Tumlinson et al., 1969), thus requiring the means to first locate the source of food and only then to produce the pheromone. However, in the aforementioned study, behavioral bioassays were not carried out in order to assess whether a threshold as low as $1 \mathrm{ng}$ elicits any behavioral responses. Possibly, the nonpreference for Mix ${ }^{10-}$ was because the compounds within the blend were in doses lower than the detection threshold for plant odors.

Usually in a blend of volatiles, some compounds can be more important than others, and omission from a blend can either lead to a reduction in attractiveness, or have no impact at all as a consequence of redundancy in composition (Bruce and Pickett, 2011). Key compounds for host recognition in a complex volatile blend usually comprise 3-10 components (Szendrei and Rodriguez-Saona, 2010; Bruce and Pickett, 2011). Based on this information, a stepwise deletion of single compounds of synthetic Mixl was attempted in this study. The removal of (E)-2-methylbutanal oxime, $\beta$-pinene, $(Z)$-3-hexenyl acetate and $(E)$-ocimene did not affect boll weevil attraction. However, the individual deletion of any of the remaining six constituents (Final Mix), i.e., DMNT, $(R)$-linalool, methyl salicylate, $(E)-(1 R, 9 S)$ caryophyllene, geranylacetone, and TMTT, resulted in loss of boll weevil attraction, indicating that these compounds are essential for the detection of host plants.

There are three hypotheses regarding insect host location and plant volatile blends: (i) plant volatiles are highly specific and comprised of compounds found only in related species (qualitative pattern), (ii) plant odor specificity is obtained by a specific ratio of its components (quantitative pattern), and (iii) both qualitative and quantitative patterns are important 
as well as their contrast with the background odors (olfactory contrast hypothesis) (Visser, 1986; Hilker and McNeil, 2008). Our results support the third hypothesis, since the compounds here identified as attractive to the boll weevil are not exclusively found in cotton plants, and both quality and quantity of blend components seem to be important in conveying reliable information for host location by the boll weevil. In the context of agricultural pest management, the identification of redundant compounds and the consequent reduction in the number of components of a blend, whether for attraction or pest repellence, is an important factor when considering aspects of applicability and production cost of control methods (Collatz and Dorn, 2013). However, oversimplification of complex blends can result in their inefficiency. In the bioassays, individual solutions of Final Mix components, DMNT, (R)-linalool, methyl salicylate, $(E)-(1 R, 9 S)$-caryophyllene, geranylacetone and TMTT, at the same concentration as found in boll weevil-induced volatiles of cotton at the reproductive stage, were no more attractive than the hexane control. Non-response to individual compounds has already been reported in the literature for several insect species, such as Cydia molesta (Busck) (Lepidoptera: Tortricidae); Sitodiplosis mosellana (Géhin) (Diptera: Cecidomyiidae) and Sitophilus zeamais (Motschulsky) (Coleoptera: Curculionidae) (Natale et al., 2003; Birkett et al., 2004; Ukeh et al., 2012). In general, when plant volatiles are individually detected outside the context of a specific mixture, they can be interpreted as cues from non-host plants. However, when they are together, they may represent a completely different signal (Bruce and Pickett, 2011).

The identification of cotton volatiles that encode host recognition for A. grandis adults provide a basis for the development of innovative crop protection methods. The

\section{REFERENCES}

Beltrão, N. E. M., and Azevedo, D. M. P. (2008). O Agronegócio do Algodão no Brasil. Brasília: Embrapa Informação Tecnológica.

Birkett, M. A., Bruce, T. J., Martin, J. L., Smart, L. E., Oakley, J., and Wadhams, L. J. (2004). Responses of female orange wheat blossom midge, Sitodiplosis mosellana, to wheat panicle volatiles. J. Chem. Ecol. 30, 1319-1328. doi: 10.1023/B:JOEC.0000037742.05022.9f

Bruce, T. J., and Pickett, J. A. (2011). Perception of plant volatile blends by herbivorous insects - finding the right mix. Phytochemistry 72, 1605-1611. doi: 10.1016/j.phytochem.2011.04.011

Bruce, T. J., Wadhams, L. J., and Woodcock, C. M. (2005). Insect host location: a volatile situation. Trends Plant Sci. 10, 269-274. doi: 10.1016/j.tplants.2005.04.003

Collatz, J., and Dorn, S. (2013). A host-plant-derived volatile blend to attract the apple blossom weevil Anthonomus pomorum - the essential volatiles include a repellent constituent. Pest Manag. Sci. 69, 1092-1098. doi: 10.1002/ ps.3477

Dickens, J. C. (1984). Olfaction in the boll weevil, Anthonomus grandis Boh. (Coleoptera: Curculionidae): electroantennogram studies. J. Chem. Ecol. 10, 1759-1785. doi: 10.1007/BF00987360

Dickens, J. C. (1986). Orientation of boll weevil, Anthonomus grandis Boh. (Coleoptera: Curculionidae), to pheromone and volatile host compound in the laboratory. J. Chem. Ecol. 12, 91-98. doi: 10.1007/BF01045593

Dickens, J. C. (1989). Green leaf volatiles enhance aggregation pheromone of boll weevil, Anthonomus grandis. Entomol. Exp. Appl. 52, 191-203. doi: 10.1111/j.1570-7458.1989.tb01268.x discovery that plant odors can enhance the attractiveness of pheromones allowed the establishment of new technologies for the monitoring and mass collection of pests (Piñero and Prokopy, 2003). A two-year field experiment using traps baited with cotton-derived compounds identified here and the boll weevil's aggregation pheromone is being undertaken, which might help in the development of semiochemical-based weevil management.

\section{AUTHOR CONTRIBUTIONS}

$\mathrm{DM}, \mathrm{MB}-\mathrm{M}, \mathrm{MB}$, and RL conceived the ideas and designed methodology. DM, CW, DW, and MB-M collected the data. DM, MB-M, CW, JP, and MAB analyzed the data. DM and MB-M led writing of the manuscript. All authors contributed critically to the drafts and gave final approval for publication.

\section{ACKNOWLEDGMENTS}

We thank Hélio Moreira dos Santos for helping with laboratory rearing of boll weevils and Dr. Fabio Aquino de Albuquerque for providing cotton seeds. We also thank the Post-Graduate Zoology Program of the University of Brasília (UnB) for use of their facility. This work received financial support from the Coordination of Superior Level Staff Improvement (CAPES) through a grant to DM (no. 99999.014964/2013-09), National Council of Technological and Scientific Development (CNPq), Federal District Research Foundation (FAP-DF) and the Brazilian Corporation of Agricultural Research (EMBRAPA). Rothamsted Research received grant-aided support from the Biotechnology and Biological Sciences Research Council (BBSRC) of the United Kingdom.

Dickens, J. C. (1990). Specialized receptor neurons for pheromones and host plant odours in the boll weevil, Anthonomus grandis Boh. (Coleoptera: Curculionidae). Chem. Senses 15, 311-331. doi: 10.1093/chemse/15.3.311

Dudareva, N., Pichersky, E., and Gershenzon, J. (2004). Biochemistry of plant volatiles. Plant Physiol. 135, 1893-1902. doi: 10.1104/pp.104.049981

Gouinguené, S. P., and Turlings, T. C. (2002). The effects of abiotic factors on induced volatile emissions in corn plants. Plant Physiol. 129, 1296-1307. doi: 10.1104/pp.001941

Hallem, E. A., Dahanukar, A., and Carlson, J. R. (2006). Insect odour and taste receptors. Ann. Rev. Entomol. 51, 113-135. doi: 10.1146/annurev.ento.51.051705.113646

Hilker, M., and McNeil, J. (2008). "Chemical and behavioural ecology in insect parasitoids: how to behave optimally in complex odorous environment," in Behavioral Ecology of Insect Parasitoids: from Theoretical Approaches to Field Applications, ed E. Wajnber (Oxford: Blackwell Publishing), 92-128.

Kessler, A., and Baldwin, I. T. (2001). Defensive function of herbivoreinduced plant volatile emissions in nature. Science 291, 2141-2144. doi: $10.1126 /$ science.291.5511.2141

Leopold, E. J. (1990). Selective hydroboration of a 1, 3, 7-triene: homogeraniol. Org. Synth. 64, 164-171.

Magalhães, D. M. (2016). Aspects of Insects and Plants Chemical Ecology: Interactions of Anthonomus grandis Boh. (Coleoptera: Curculionidae) and Cotton. Ph.D. thesis, University of Brasília, Brasília.

Magalhães, D. M., Borges, M., Laumann, R. A., Sujii, E. R., Mayor, P., Caulfield, J. C., et al. (2012). Semiochemicals from herbivory induced cotton plants enhance the foraging behaviour of the cotton boll weevil, Anthonomus grandis. J. Chem. Ecol. 38, 1528-1538. doi: 10.1007/s10886-012-0216-5 
Magalhães, D. M., Borges, M., Laumann, R. A., Woodcock, C. M., Pickett, J. A., Birkett, M. A., et al. (2016). Influence of two acyclic homoterpenes (tetranorterpenes) on the foraging behaviour of Anthonomus grandis Boh. J. Chem. Ecol. 42, 305-313. doi: 10.1007/s10886-016-0691-1

McKibben, G. H., Mitchell, E. B., Scott, W. P., and Hedin, P. A. (1977). Boll weevils are attracted to volatiles oils from cotton plants. Environ. Entomol. 6, 804-806. doi: 10.1093/ee/6.6.804

Michereff, M. F., Laumann, R. A., Borges, M., Michereff-Filho, M., Diniz, I. R., Farias-Neto, A. L., et al. (2011). Volatiles mediating a plant-herbivore-natural enemy interaction in resistant and susceptible soybean cultivars. J. Chem. Ecol. 37, 273-285. doi: 10.1007/s10886-011-9917-4

Natale, D., Mattiacci, L., Hern, A., Dorn, S., and Pasqualini, E. (2003). Response of female Cydia molesta (Lepidoptera: Tortricidae) to plant derived volatiles. $B$. Entomol. Res. 93, 335-342. doi: 10.1079/BER2003250

NIST (2008). Software NIST/EPA/NIH Mass Spectral Library. Available online at: https://chemdata.nist.gov/dokuwiki/doku.php?id=chemdata:downloads:start

Papa, G., and Celoto, F. J. (2015). "Controle químico do bicudo-do-algodoeiro, Anthonomus grandis, Boheman (Coleoptera: Curculionidae)," in O Bicudo-doAlgodoeiro (Anthonomus grandis Boh., 1843) nos Cerrados Brasileiros: Biologia e Medidas de Controle, ed J. L. Belot (Cuiabá: Boletim de P\&D Instituto Mato-grossense do Algodão), 95-116.

Paré, P. W., and Tumlinson, J. H. (1999). Plant volatiles as a defence against insect herbivores. Plant Physiol. 121, 325-331. doi: 10.1104/pp.121.2.325

Piñero, J. C., and Prokopy, R. J. (2003). Field evaluation of plant odour and pheromonal combinations for attracting plum curculios. J. Chem. Ecol. 29, 2735-2748. doi: 10.1023/B:JOEC.0000008017.16911.aa

Ribeiro, P. A., Sujii, E. R., Diniz, I. R., Medeiros, M. A., Salgado-Labouriau, M. L., Branco, M. C., et al. (2010). Alternative food sources and overwintering feeding behaviour of the boll weevil, Anthonomus grandis Boehman (Coleoptera: Curculionidae), under the tropical conditions of Central Brazil. Neotrop. Entomol. 39, 28-34. doi: 10.1590/S1519-566X20100001 00005

Riffell, J. A., Lei, H., Christensen, T. A., and Hildebrand, J. G. (2009). Characterization and coding of behaviourally significant odour mixtures. Curr. Biol. 19, 335-340. doi: 10.1016/j.cub.2009.01.041

Rodrigues, S. M. M., and Miranda, J. E. (2015). "Controle etológico do bicudodo-algodoeiro," in O Bicudo-do-Algodoeiro (Anthonomus grandis Boh., 1843) nos Cerrados Brasileiros: Biologia e Medidas de Controle, ed J. L. Belot (Cuiabá: Boletim de P\&D Instituto Mato-grossense do Algodão), 143-154.

Rodriguez-Saona, C., and Stelinski, L. L. (2009). "Behaviour-modifying strategies in IPM: theory and practice," in Integrated Pest Management: InnovationDevelopment Process, ed R. Peshin and R. Dhawan (Dordrech: Springer), 263-315.

Rostás, M., Jurriaan, T., Mauch-Mani, B., and Turlings, T. C. J. (2006). Fungal infection reduces herbivore-induced plant volatiles of maize but does not affect naive parasitoids. J. Chem. Ecol. 32, 1897-1909. doi: 10.1007/s10886-006-9147-3

Rummel, D. R., and Curry, G. L. (1986). "Dinâmica populacional e níveis de dano econômico," in O Bicudo do Algodoeiro, ed S. Barbosa S, M. J. Lukefarh, and R. B. Sobrinho (Brasília: Embrapa Departamento de Difusão Tecnológica Documentos), 201-220.
Sappington, T. W., and Spurgeon, D. W. (2000). Preferred technique for adult sex determination of the boll weevil (Coleoptera: Curculionidae). Ann. Entomol. Soc. Am. 93, 610-615. doi: 10.1603/0013-8746(2000)093[0610:PTFASD]2.0. $\mathrm{CO} ; 2$

Schmidt, F. G. V., Monnerat, R., Borges, M., and Carvalho, R. (2001). Criação de Insetos Para Avaliação de Agentes Entomopatogênicos e Semioquímicos. Brasília: Embrapa Recursos Genéticos e Biotecnologia.

Silva, J. B., Silva-Torres, C. S. A., Blassioli-Moraes, M. C., Torres, J. B., Laumann, R. A., and Borges, M. (2015). Interaction of Anthonomus grandis and cotton genotypes: biological and behavioral responses. Entomol. Exp. App. 156, 238-253. doi: 10.1111/eea.12326

Szendrei, Z., and Rodriguez-Saona, C. (2010). A meta-analysis of insect pest behavioural manipulation with plant volatiles. Entomol. Exp. Appl. 134, 201-210. doi: 10.1111/j.1570-7458.2009.00954.x

Tumlinson, J. H., Hardee, D. D., Gueldner, R. C., Thompson, A. C., Hedin, P. A., and Minyard, J. P. (1969). Sex pheromone produced by the male boll weevil: isolation, identification, and synthesis. Science 166, 1010-1012. doi: $10.1126 /$ science. 166.3908 .1010

Turlings, T. C. J., Alborn, H. R., Loughrin, J. H., and Tumlinson, J. H. (2000). Volicitin, an elicitor of maize volatiles in oral secretion of Spodoptera exigua: isolation and bioactivity. J. Chem. Ecol. 26, 189-202. doi: 10.1023/A:1005449730052

Ukeh, D. A., Woodcock, C. M., Pickett, J. A., and Birkett, M. A. (2012). Identification of host kairomones from maize, Zea mays, for the maize weevil, Sitophilus zeamais. J. Chem. Ecol. 38, 1402-1409. doi: 10.1007/s10886-012-0191-x

Visser, J. H. (1986). Host odour perception in phytophagous insects. Ann. Rev. Entomol. 31, 121-144. doi: 10.1146/annurev.en.31.010186.001005

Voegel, A. I. (1956). "Reactions and characterisation of aromatic aldehydes," in Practical Organic Chemistry, Including Qualitative Organic Analysis, ed A. I. Voegel (New York, NY: Longman), 720-725.

Webster, B., Bruce, T., Dufour, S., Birkemeyer, C., Birkett, M., Hardie, J., et al. (2008). Identification of volatile compounds used in host location by the bean aphid, Aphis fabae. J. Chem. Ecol. 34, 1153-1161. doi: 10.1007/s10886-008-9510-7

Webster, B., Bruce, T., Pickett, J. A., and Hardie, J. (2010). Volatiles functioning as host cues in a blend become no host cues when presented alone to the black bean aphid. Anim. Behav. 79, 451-457. doi: 10.1016/j.anbehav.2009.1 1.028

Conflict of Interest Statement: The authors declare that the research was conducted in the absence of any commercial or financial relationships that could be construed as a potential conflict of interest.

Copyright ( 2018 Magalhães, Borges, Laumann, Woodcock, Withall, Pickett, Birkett and Blassioli-Moraes. This is an open-access article distributed under the terms of the Creative Commons Attribution License (CC BY). The use, distribution or reproduction in other forums is permitted, provided the original author(s) and the copyright owner(s) are credited and that the original publication in this journal is cited, in accordance with accepted academic practice. No use, distribution or reproduction is permitted which does not comply with these terms. 